the higher regions of the atmosphere over an area equal to that of Europe. That this is not fanciful is proved by the behaviour of smoke. I have often watched when at sea, on a still, calm day, the black smoke of some passing steamer rise to some determined height, and then gradually spread itself at an equal and constant distance from the sea like a great flat pall. I have also seen on land the smoke from some manufacturing shaft blown gently by the wind follow the curves of the land, remaining always at the same distance from the ground, but gradually spreading outwards in every direction. I have also seen two lines of smoke refuse to coalesce, but repelling each other exactly as they ought if they were similarly electrified. That smoke is, therefore, negatively electrified I firmly believe, though I have never tested it. Now, that this wonderful atmospheric disturbance was accompanied by extraordinary electrical disturbance was shown, not only by Capt. Watson's observations near the spot, but by Prof. Smith's records at Madras, and hence it requires no great stretch of the imagination to conceive electricity playing a great part in the recent gorgeous display of atmospheric effects."

IN reference to Mr. Preece's letter, Mr. Crookes writes:- "In a paper read before the Royal Society in I879 I sbowed that at a rarefaction of the millionth of an atmosphere two pieces of electrified gold leaf repelled one another at a considerable angle for thirteen months without loss of charge. Therefore at a rarefaction of a millionth (corresponding to a height above the earth's surface of about sixty-two miles) air is a perfect nonconductor of statical electricity, without interfering with the mutual repulsion of similarly electrified particles. When we bear in mind that the specific gravity of gold is five or six times that of the rock whose disruption formed the dust in question, and that the size of the individual particles of dust is certainly many thousand times smaller than my gold leaves, there is every reason to believe that electrified dust, once projected fifty or sixty miles above the earth's surface, might remain there fur many years."

BISHOP BROMBY, writing to the Times, says that in a letter from a member of his family at Hobart, Tasmania, the writer speaks admiringly of "the loveliest after-glow which was spread over the sky on the other side of the water where the sun had set." This was written on October 12 by one who was ignorant that similar phenomena had been observed in other parts of the world.

ANOTHER correspondent of the Times states that in a letter dated "Duem, September 24, I883," Hicks Pasha wrote:- "By the way, have you in England noticed a large black spot on the sun? To-day, when it rose, it was of a pale green colour, and we saw through our glasses an immense black spot on the lower half of it. What does this portend? I feel sure there must be some notice of it in the papers in England."

SHERIFF RAMPINI of Lerwick, Shetland, writes that the sunsets have been observed in these northern islands.

MR. G. F. BURDER of Clifton sends the following extract from a letter from a passenger travelling from San Francisco to Sydney, three days after leaving Honolulu. The writer says:- "On Wednesday, September 5, we witnessed a most curious phenomenon. The sun set perfectly blue, and next morning it rose a flaming ball of blue The blue light was reflected in our cabins."

ON November 30, at 4 p.m., another remarkable sunset was observed in Stockholm. A correspondent states that the western sky became covered with an intense purple. after-glow, having the appearance of an enormous distant conflagration, which nearly reached the zenith, and lasted for an hour, even after it was dark, and the stars were visible. On the morning of December 1 a similar intense light was observed at sunrise. The colour was, however, then more yellow. The phenomena have also been observed in the north of Sweden, in Gothenburg, in Christiania, and in Copenhagen.

\section{THE KRAKATOA AIR-WAVE}

$\mathrm{O}^{\mathrm{N}}$ Thursday last Mr. R. H. Scott communicated a paper to the Royal Society giving a map and tabular statements concerning certain barometric disturbances observed towards the end of August last.

The obvious correspondence of the forms and times of occurrence of the barometric disturbances, described in Mr. Scott's paper, at once suggested to General Strachey that they were due to a common origin, and the great volcanic eruption at Krakatoa in the Straits of Sunda appeared to supply a probable efficient cause. General Strachey therefore took up the question from this point of view, and at the same meeting communicated a paper, of which the following is an abstract :-

"Any shock of sufficient violence might be expected to produce an atmospheric wave, advancing from the place where it was caused in a circular form round the globe, at first expanding until it bad got half round the earth, and then ayain contracting till it was again concentrated at the antipodes, from which again it would be thrown back, and so pass backwards and forwards till it was obliterated. It might have been expected that such a wave would travel with the velocity of sound, being probably of the same nature as that which causes sound, though the vibrations had not the peculiar character that affects our organs of hearing. It has, however, been suggested to me that the wave may rather have had the character of a solitary wave produced in a liquid, the velocity of which in the air would not materially differ from that of sound. ${ }^{1}$

"A rough examination of the facts at first made known by the observations recorded in Great Britain indicated that there was prima facie strong evidence in support of this view, and that the pbenomena would be approximately explained by the passage round the earth of a series of waves travelling at the rate of about 700 miles an hour in opposite directions from the place where the volcanic truption occurred. The records since procured from other places, and the more careful examination of the facts, have quite confirmed this conclusion.

"Although we may expect to obtain additional data from other parts of the globe, which will make the investigation of this somewhat remarkable phenomenon more complete, yet those we now have are sufficient to justify an attempt being made to bring the more important facts before the Royal Society without further delay.

"The following table shows the stations from which the records have been received of which use bas been made in this discussion, with certain particulars of their geographical position, and of their distances mea ured on great circles, from Krakatoa, the place of eruption :-

\begin{tabular}{|c|c|c|c|c|}
\hline \multirow{2}{*}{ Place } & \multirow{2}{*}{ Longitude } & \multirow{2}{*}{ Latitude } & \multicolumn{2}{|c|}{$\begin{array}{c}\text { Distance frum Kraka } \\
\text { toa, measured on a } \\
\text { great circle }\end{array}$} \\
\hline & & & $\begin{array}{c}\text { From west } \\
\text { to east. }\end{array}$ & $\begin{array}{l}\text { From east } \\
\text { to west. }\end{array}$ \\
\hline Toronto . & W. 79 I 15 & N. $434^{\prime}$ & I ${ }_{42} \dot{1}_{5}$ & 21745 \\
\hline Valencia ................ & , 1018 &,, 5155 & 24931 & I10 29 \\
\hline Coimbra ............... & , 824 & ", 4013 & 24758 & 1122 \\
\hline Armagh .... & 639 &, 5421 & 252 I 7 & 10743 \\
\hline Falmouth ............ & 54 &, 509 & 25215 & 10745 \\
\hline Glasgow ............. & 4 I8 &,, 5553 & 25357 & I06 3 \\
\hline Stonyhurst .. ........ & 228 &, 5351 & 25434 & 10526 \\
\hline Aberdeen $\quad . . . . . . . .$. & 26 &, 5710 & 25525 & 10435 \\
\hline Kew...................... & 019 &,$\quad 5 \mathbf{I} 28$ & 25527 & 10433 \\
\hline Greenwich ... & 00 &,, 5 I 29 & 25539 & IO4 2 I \\
\hline Paris............... & 220 & , $485^{\circ}$ & 25649 & 10311 \\
\hline Brussels .............. & ," 420 &, $505 \mathrm{I}$ & 25817 & IOI 43 \\
\hline St. Petersburg $\ldots . .$. & " 3020 & , , 5955 & 2723 & 8757 \\
\hline Krakatoa............... &, , 10522 & S. 69 & & \\
\hline
\end{tabular}

I The $\log$ of a surveying ship at the north of Borneo, since received, shows that the explosions were heard there on the morning of August 27, at a distance of $\mathrm{r} 2 \mathrm{co}$ miles from the volcano; and it has been also stated that these sounds were heard in Ceylon, at a distance of about 2000 miles. -R.S. 
"As the earlier disturbances, on August 27 and 28, extend over several hours, it became necessacy to fix on certain sufficiently well defined points in the curves representing the barometric pressure, from which to measure the epochs of the passage of successive disturbances. The first and second of the series are, in almost all the curves, well defined and generally similar in form, commencing with a distinct rise, which is again followed by a distinct fall, the fall being shorter than the rise. These features are followed by a less definite rise succeeded by a shallow fall, after which there is again a rise, which gradually paszes into the more regular trace.

"The third and fourth of the disturbances can be traced in all the curves, but they no longer exhibit the same characters, and are usually $\mathrm{n}$ thing more than a sudden sharply defined rise, though in front of some of these there is a more or less distinct trace of a hollow.

"The fifth and sixth of the series become less distinct and are lost at several stations, being usually rises; while a seventh faint disturbance, as a shallow hollow, can be traced in a few of the curves, after which nothing can be distinguished.

" By a comparison of the time intervals between the first and third, the third and fifth, and the fifth and seventh disturbances, and assuming (which the facts seem to justify) that the velocity of the wave has remained unchanged in its passage from east to west, it would appear that the first well-defined rise in the first of the series corresponds to the rises which are prominent in those succeeding it. And the same conclusion has been drawn from an examination of the second and fourth compared with the fourth and sixth of the series.

"Adopting these conclusions, the times of the successive passages of the initial rise have been measured from the curves, stuitable allowance having been made where the rise was difficult to trace, or, as sometimes happened, a hollow appeared corre sponding in position with the hollows in the earlier form of the disturbances. There is, of course, some doubt attaching to these measurements, but their general consistency seems to indicate that they may be accepted as fairly representing the facts under discussion.

"The following table gives the results of these estimates of the times at which the successive waves passed the several stations, reckoned from midnight of Aug. 26, in Green wich mean time :-

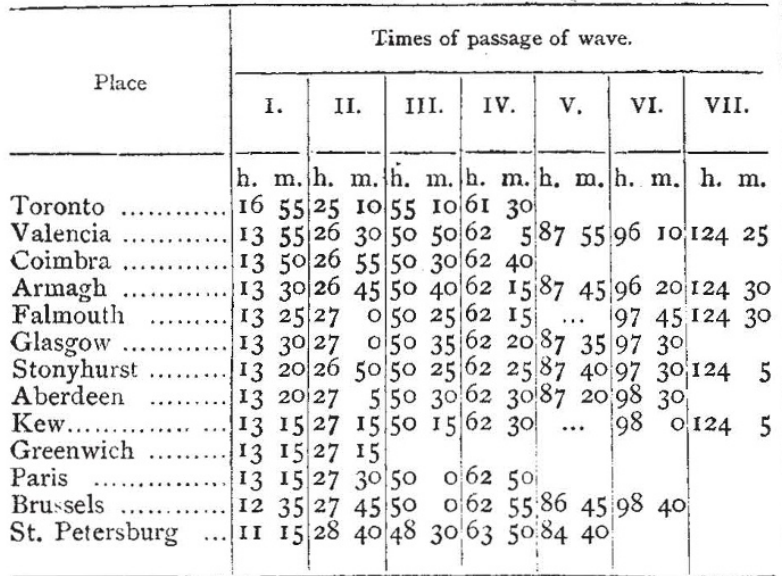

"From these figures are dedaced the intervals beiween the succe, sive passages of the waves from east to west, and from west to east, respectively, or of the times of travelling round the earth, which are shown in the next table, for all stations excepting Toronto.

"From the results thus obtained it would follow that the wave travelled round the earth from east to west in $36 \mathrm{~h}$. $57 \mathrm{~m}$., being at the rate of '1026 hour for one degree of a great circle of the earth, and from west to east in $35 \mathrm{~h}$. $17 \mathrm{~m} ., \mathrm{b}$ ing at the rate of . 098 hour for one degree. From the velocities thus determined the probable time of the origin of the wave has been calculated from the known distance of each place from Krakatoa, the time occupied in the passage of the wave from Krakatoa to the place of observation, and the observed time of the passage of the waves.

"The mean value thus obtained from the waves moving from east to west for the time of the $v$ igin of the disturbance at
Intervals occupied in travelling round the earth.

\begin{tabular}{|c|c|c|c|c|c|c|c|}
\hline \multirow{2}{*}{ Plase. } & \multicolumn{4}{|c|}{ From east to west. } & \multicolumn{3}{|c|}{ From west to east. } \\
\hline & $\begin{array}{l}\text { I. } \\
\text { to } \\
\text { III. }\end{array}$ & $\begin{array}{l}\text { III. } \\
\text { to } \\
\text { V. }\end{array}$ & $\begin{array}{l}\text { V. } \\
\text { to } \\
\text { VII. }\end{array}$ & Mean. & $\begin{array}{l}\text { II. } \\
\text { to } \\
\text { IV. }\end{array}$ & $\begin{array}{l}\text { IV. } \\
\text { to } \\
\text { VI. }\end{array}$ & Mean. \\
\hline $\begin{array}{l}\text { Valencia ... } \\
\text { Coimbra ... } \\
\text { Armagh...... } \\
\text { Falmouth ... } \\
\text { Glasgow ... } \\
\text { Stonyhurst } \\
\text { Aberdeen .... } \\
\text { Kew .......... } \\
\text { Greenwich } \\
\text { Paris ........... } \\
\text { Brussels...... } \\
\text { St.Petersbrg. }\end{array}$ & $\begin{array}{rr}\text { h. } & \text { m. } \\
36 & 55 \\
36 & 40 \\
37 & \text { ro } \\
37 & 0 \\
37 & 5 \\
37 & 5 \\
37 & \text { ro } \\
37 & 0 \\
36 & 45 \\
36 & 45 \\
37 & 25 \\
37 & 15\end{array}$ & $\mid \begin{array}{cc}37 & \mathrm{~m} . \\
& \ldots \\
37 & 5 \\
37 & 3^{*} \\
37 & \mathrm{o} \\
37 & \mathrm{I} \\
36 & 50 \\
36 & 55^{*} \\
& \ldots \\
36 & 45 \\
36 & 10\end{array}$ & 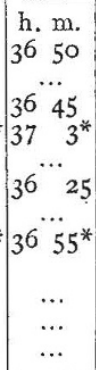 & $\begin{array}{lr}\text { h. } & \mathrm{m} . \\
36 & 57 \\
36 & 40 \\
37 & \mathrm{o} \\
37 & 2 \\
37 & 3 \\
36 & 55 \\
37 & 0 \\
36 & 57 \\
& \\
36 & 45 \\
37 & 5 \\
36 & 43\end{array}$ & $\begin{array}{ll}\text { h. } & \mathrm{m} . \\
35 & 35 \\
35 & 45 \\
35 & 30 \\
35 & 15 \\
35 & 20 \\
35 & 35 \\
35 & 25 \\
35 & 15 \\
& \\
35 & 20 \\
35 & 10 \\
35 & 10\end{array}$ & $\begin{array}{lr}\text { h. } & \text { m. } \\
34 & 5 \\
\ldots & \\
34 & 5 \\
35 & 30 \\
35 & 10 \\
35 & 5 \\
36 & 0 \\
35 & 30 \\
& \ldots \\
35 & 45 \\
& \ldots\end{array}$ & $\begin{array}{ll}\text { h. m. } \\
34 & 50 \\
33 & 45 \\
34 & 48 \\
35 & 22 \\
35 & 15 \\
35 & 20 \\
35 & 43 \\
35 & 23 \\
35 & 20 \\
35 & 28 \\
35 & 10\end{array}$ \\
\hline $\left.\begin{array}{c}\text { Mean ex- } \\
\text { cluding } \\
\text { Toronto }\end{array}\right\}$ & $37 \quad 4$ & 3654 & $364^{8}$ & 3657 & 3524 & 359 & $35 \mathrm{I} 7$ \\
\hline
\end{tabular}

Krakatoa is $2.52 \mathrm{~h}$. Greenwich mean time, or $9.53 \mathrm{~h}$. local time, that is 9 h. $32 \mathrm{~m}$. a.m. of August 27.

"In like manner the waves travelling from west to east gave results which were exhibited in another table.

"The mean value of the time of the origin of the disturbance obtained from the waves moving from west to east is therefore $2^{\prime} 20 \mathrm{~h}$. Greenwich mean time, or $9^{*} \mathrm{Ih}$. local time, that is, $9 \mathrm{~h}$. I $3 \mathrm{~m}$. local time.

"The mean between the two values obtained from the waves travelling against the earth's motion of revolution, and those travelling with it is $2 \mathrm{~h} .24 \mathrm{~m}$. Greenwich mean time, or $9 \mathrm{~h} .24 \mathrm{~m}$. local time, August 27.

"The velocity of the waves in miles will be for those which travel from east to west 674 miles per hour, and for those passing from west to east 706 miles per hour. The velocity of sound is for a temperature of $50^{\circ} \mathrm{F} .757$ miles an hour, and for $80^{\circ} \mathrm{F}$. 781 miles an hour. With a temperature as low as zero $\mathrm{F}$. the velocity will only be reduced to 723 miles an bour, which is still considerably in excess of the greater of the observed velocities. The excess of the velocity of the waves which travelled in the same direction as the earth's motion of revolution, that is, from west to east, over that of those which pas ed in the opposite direction, is about 32 miles an hour, which might be accounted for by the circumstance that the winds along the paths of the wave; would, on the whole, be from the west, which would cause an increase in the velocity of the one set, and a diminution in that of the other, so that the observed difference of 32 miles would correspond to an average westerly wind of 16 miles an hour, which is not improbable.

"It should be observed that the path of the wave which passed Toronto approached very near to the North and South Poles, and that the velocity in both directions appeared to be somewhat less than in the waves which passed over Central Europe. The wave which passed northwards over Asia travelled at the rate of about 660 miles an hour, or about 15 mile: an hour slower than the wave which passed over Great Britain from east to west. This reduction of velocity seems to be within the limits of what might be due to the low temperature of the regions.

"The wave travelling from east to west having been perceptible on the barometer traces at several of the stations until about 122 hours after its origin, and its velocity having been 674 miles an hour, it had travelled before its extinction more than 82,200 miles, and had passed $3{ }_{4}^{1}$ times ruand the entire circuit of the earth.

"It is further worthy of notice that during August 30 and $3 \mathrm{I}$ and September $\mathrm{I}$, a very severe cyclonic storm was crossing the North Atlantic, and that the wave coming from the westward early on the 31 st, No. VI. of the series, must have passed on in front of the cyclone, and that its next transit would have carried it into the very centre of the cyclone near the British Isles on the afternoon of Sentember I. This perhaps ac-

* At these stations the fifth transit cannot be traced.

I It has not been thonght necessary $t$, give in extenso the table showing the separate values deduced from the several observations, but they differ from the mean by in no case more than a few minutes. 
counts for no trace of it being found, though the wave coming from the eastward on the morning of that day, just before the cyclone had arrived, No. VII., was discernible.

"There is no definite statement, so far as I am informed at present, of the true time of any particularly severe shock or explosion at Krakatoa excepting that whieh is contained in the letter of Mr. Watson (published in NATURE, December 6, 1883), whose ship was within a few miles of the volcano on the morning of August 27. He refers to an unusually severe explosion as having occurred at $\mathrm{Irh}$. $15 \mathrm{~m}$. a.m. local time, which is nearly 45 minutes later than the time, $9 \mathrm{~h}, 32 \mathrm{~m}$, , arrived at in the foregoing discussion. The point of the disturbance (as indicated by the barograms) which has been taken as the front of the wave is the bighest point of the first abrupt rise of the trace, and is perhaps, on an average, not far from one hour after the first signs of disturbance, the increase of pressure having been very rapid during the interval, but broken into two or three steps or oscillations. During the following half hour there is usually a large decrease of pressure, cucceeded by another abrupt rise lasting about half an hour. Then follow a fall of about an hour, then a rise of an hour and a half, and then a fall of an hour and a quarter. The whole length of the disturbance on the time scale is between five and six hours, corresponding to an actual distance of between 3500 miles and 4000 miles. The length of the first main wave of the disturbance is about one hour on the time scale, or about 700 miles in length over the earth's surface.

"In the present position of our knowledge of the facts, it can only be surmised that the shock of $1 \mathrm{rb}$. $15 \mathrm{~m}$. a.m. of August 27, otserved by $\mathrm{Mr}$. Watson, corresponds to the second main feature of the disturbance. That the wave which forms the first feature would have originated at IIh. I $5 \mathrm{~m}$. a.m. is apparently inconsistent with the observed velocities, which it has been shown are remarkably con:istent, and indicate without much doubt an origin at $9 \mathrm{~b} .32 \mathrm{~m}$. a.m.

"The barometric disturbance at Mauritius noted by Dr. Meldrum is said to have begun soon after II a.m. local time. The distance from the volcano to Mauritius being about 3450 miles, the wave at the rate of 674 miles per hour would have reached the island in $5 \mathrm{~h} .7 \mathrm{~m}$. Taking the great shock at $2 \mathrm{~h} .32 \mathrm{~m}$. Greenwich mean time, as before reckoned, the wave would reach Mauritius at $7 \mathrm{~h} .39 \mathrm{~m}$. Greenwich mean time, or adding the allowance for difference of longitude, $3 \mathrm{~h}$. 50m., the local time would be $I x h$. $29 \mathrm{~m}$., which agrees satisfactorily with the facts as recorded.

"In conclusion, it may be noticed that the sea-waves produced by this volcanic disturbance, assuming the time of its occurrence to have been $2 \mathrm{~b} .32 \mathrm{~m}$. Greenwich mean time on August 27 , nere propagated with an approximate velocity of 480 miles an hour to Mauritius, of 430 miles an hour to Port Elizabeth near the Cape of Good Hope, and 420 miles to Galle, and a somewhat slower rate to Aden. The details of the occurrence of these waves on the coassts of India и ill shortly be laid before the Society by Major Baird, who has informed me that the velocity of the wave between Galle and Aden was 378 miles an hour, and the lengths of the great waves from 287 to 630 miles."

"P.S.-December I5. Since the above was read before the Royal Society a copy of the barometric trace from New Yurk has been received, which shows disturbances very similar to those recorded at Toronto, and at times which are quite in accordance with the general conclusions stated in the paper."

\section{NOTES}

IN connection with the resignation of Prof. Sylvester of his Chair in the Johns Hopkins University, we find that it was resolved at a meeting of the trustees held October I, "That as this resignation is doubtless the result of mature reflection on the part of Prof. Sylvester, it is hereby accepted, but that in doing so the Board of Trustees cordially extend to him its hearty thanks for the invaluable services which he has rendered to the University, and also its profound sense of the great ability, the conscientious fidelity, and untiring energy with which he has discharged the arduous duties of his Chair, thereby elevating the science of mathematics to its proper plane, not only in this finstitution but in this country." It was also resolved
"That Prof. Sylvester be appointed Professor Emeritus in the Johns Hopkins University."

Ir may be remembered that at the recent Geodetic Congress the French delegates opposed the adoption of Greenwich as the universal meridian, though $\mathrm{M}$. Faye was in favour of the adoption of Greenwich time. At the meeting of the Paris Academy on December 3, M. Faye, whilst supporting the proposal that the universal time should be that of Greenwich, stipulates for the civil hour instead of the astronomical hour, and for the counting of longitudes from $\mathrm{oh}$. to $\mathbf{I} 2 \mathrm{~h}$. positive towards the east and negative towards the west, instead of from oh, to $24 \mathrm{~h}$, reckoned towards the ea:t, but leaving it to astronomers and navigators to employ at discretion for the universal time that according to civil or astronomical reckoning, as may seem best.

A meEting was held in Sheffield last week for the purpose of carrying out, in connection with Firth College, a proposed technical department having reference to the trade of the district. Among those who spoke were Mr. Mundella and Dr. Sorby, and we need not say that all agreed as to the desirability of establishing such a department, and the necessity of educating our captains, as well as our privates, of industry, in the principles of their crafts. For that, Mr. Mundella insisted, is the true technical education. He gave the experience of a friend who has just been visiting the United States, and inspected the means for technical education existing there; the distinct conclusion was "that there is more skill and intelligence in American industrial pursuits than there is in our English industrial pursuits." It is much that we know our weakness and are taking means to remedy it. No donbt the Firth College will soon have a well equipped technical department.

THE Lecture Arrangements at the Royal Institution before Easter, 1884, are as follows :--Prof. Dewar, six lectures (adapted to a juvenile auditory) on Alchemy (in relation to modern science), commencing on Thursday next (December 27); Mr. R. S. Poole, two lectures on the Interest and Usefulness of the Study of Coins and Medals; Mr. A. Geilie, five lectures on the Origin of the Scenery of the British Isles; Prof. J. G. McKendrick, five lectures on Animal Heat : its Origin, Distribution, and Regulation; Prof. Ernst Pater, six lectures on the History and Development of the Music for the Pianoforte, and its Predecessors the Clavecin, Harpsichord, \&c. ; Prof. Tyndall, :ix lectures on the Older Electricity, its Phenomena and Investigators; Prof. Henry Morley, six lectures on Life and Literature under Charles I. ; and Capt. Abney, six lectures on Photographic Action, considered as the Work of Radiation. The Friday Evening Meetings begin on January 18, Prof. Tyndall on Rainbows. The discourses on the other evenings will probably be as follows:Rev. T. G. Bonney, the Building of the Alps; Prof. Ma Miiller, Râjah Râmmohun Roy; Mr. G. J. Romanes, the Darwiuian Theory of Instinct ; Prof. Thorpe, the Chemical Work of Wöhler; Sir Frederick Bramwell, London (below bridge) North and South Communication; Prof. Hughes, Theory of Magnetism (illustrated by experiments); Mr. C. V. Boys, Bicycles and Tricycles in Theory and Practice; Mr. J. N. Langley, the Physiological Aspect of Mesmerism; Mr. Waiter Besant, the Art of Fiction; Prof. O. Reynolds, the Two Manners of Motion of Water (shown by experiments).

EVERY one must wish well to the scheme for an Institute for East London, to the meeting in connection with which last Friday at the Mansion House the President of the Royal Society gave the benefit of his experience as an East End doctor forty years ago. The demand for such commodities as the Institute would furnish is strong enough; eminent men of science who have lectured in Whitechapel on their special subjects tell us 